\title{
Antenatal Care Service Utilization of Pregnant Women Attending Antenatal Care in Public Hospitals During the COVID-I9 Pandemic Period
}

This article was published in the following Dove Press journal: International Journal of Women's Health

\section{Erkihun Tadesse (D)}

Department of Epidemiology and Biostatistics, School of Public Health, College of Medicine and Health Sciences, Wollo University, Dessie, Ethiopia
Correspondence: Erkihun Tadesse Email brhaneyared07@gmail.com
Background: The recent coronavirus disease (COVID-19) pandemic has had a disastrous effect on the health-care delivery system, of mainly pregnancy-related healthcare. In order to fill the information gap in the scientific literature and in response to the limited evidence in the country, this study aims to assess the impact of the COVID-19 pandemic on antenatal care utilization among pregnant women attending public facilities in Northeast Ethiopia. Therefore, the result will be beneficial to design strategies for prioritizing maternal healthcare even with the COVID-19 pandemic period.

Methods: A facility-based cross-sectional study was conducted from February 2 to August 30, 2020 among pregnant women attending ANC services at public hospitals in Northeast Ethiopia. Thus, a total of 389 women were included in the study with a simple random sampling technique. The bi-variable and multi-variable logistic regression models were employed to identify factors significantly associated with ANC utilization. Adjusted odds ratio (AOR) with 95\% CI was estimated to show the strength of association. Finally, a $P$-value of $<0.05$ in the multivariable logistic regression analysis was used to identify predictors of antenatal care utilization.

Results: Overall, 114 (29.3\%) pregnant women had fully utilized antenatal care services during the pandemic period. Mother age $\geq 35$ years $(\mathrm{AOR}=11.79,95 \% \mathrm{CI}=1.18-117.8$ ), secondary education and above $(\mathrm{AOR}=4.74,95 \% \mathrm{CI}=1.04-21.61)$, history of stillbirth before recent pregnancy $(\mathrm{AOR}=0.007,95 \% \mathrm{CI}=0.001-0.12)$, interruption and diversion of services due to COVID-19 response $(\mathrm{AOR}=0.675,95 \% \mathrm{CI}=0.142-0.742)$, fear of COVID-19 (AOR $=0.13,95 \%$ $\mathrm{CI}=0.06-0.31)$, and lack of transport access $(\mathrm{AOR}=4.15,95 \% \mathrm{CI}=1.04-16.54)$ were predictors of full antenatal care service utilization.

Conclusion: Three of every ten pregnant women who attended the obstetric outpatient clinics have fully utilized the antenatal care services. Encouraging women's educational status, prioritizing maternal health services during COVID-19, and improving the quality of ANC service should be emphasized more.

Keywords: antenatal care, prenatal care, utilization, coronavirus disease, pregnant women, Ethiopia

\section{Introduction}

The novel coronavirus, which causes coronavirus disease (COVID-19), has spread rapidly since emerging in late 2019, and the World Health Organization (WHO) declared the disease a global pandemic on March 11, 2020. ${ }^{1}$ More than 49,373,235 confirmed cases and 1,243,083 deaths were reported globally as of October, $2020 .^{2}$ 
Antenatal healthcare is defined by the WHO as the "care a pregnant mother receives before birth", and involves education, screening, counseling, treatment of minor ailment, and immunization services. ${ }^{3}$

Antenatal care presents the first contact opportunity for a woman to connect with formal health services and linking women with pregnancy complications to a referral system. $^{4}$

Globally 303,000 maternal deaths occur due to pregnancy and childbirth-related complications each year, with 99\% of them occurring in SSA (sub-Saharan Africa) and Southern Asia. ${ }^{5-7}$ Antenatal care helps to reduce the occurrence of maternal morbidity and mortality by providing information about danger signs, health promotion, birth preparedness, and care for pregnancy complications. $^{5}$ Even though the WHO recommends a minimum of four ANC visita for pregnant women, the maternal mortality during pregnancy or within 42 days of termination of pregnancy still remains high in sub-Saharan Africa, including Ethiopia. ${ }^{5,8}$

Studies conducted in different countries reported that maternal age, number of living children, educational status, place of residence, occupation, religion, socio-economic status, and previous obstetric history were factors significantly associated with the use of antenatal care service. $^{5,-8-10}$

The COVID-19 pandemic is posing considerable challenges for countries to maintain the provision of high quality, essential maternal and newborn health services. ${ }^{11}$ Pregnant women and mothers with newborns may experience difficulties accessing services due to transport disruptions and lockdown measures or be reluctant to come to health facilities due to fear of infection. ${ }^{11}$ Thus, a modest decline of $10 \%$ in coverage of pregnancy related and newborn health-care services were reported due to pandemics. This would result in 28,000 maternal deaths. ${ }^{12} \mathrm{~A}$ recent study done in the US reported that ANC coverage reductions of $39.3-51.9 \%$, due to the pandemic, would result in 56,700 additional maternal deaths. ${ }^{12}$

In addition, disruption of maternity services and diversion of resources away from essential pregnancy care, because of prioritizing the COVID-19 response, increased risks of maternal morbidity and mortality. ${ }^{13}$ Anxiety and obsessive-compulsive symptoms in pregnant women were found to be increased during the current SARS-CoV-2 pandemic. $^{14}$

The indirect effects of COVID-19 at the population level, as a result of social restrictions, lockdown, and reorganization of health systems, has been evident in even well-resourced countries such as Singapore. ${ }^{15}$

In low-income countries, the impact of containment and preparedness policies on maternal and newborn health could be more pronounced. Even before the emergence of COVID-19, high-quality and timely maternal health-care services were unavailable, inaccessible, or unaffordable for millions of women. Now, restrictions on travel and gatherings, health facilities with limited infection prevention supplies and unreliable infection control practices, and disrupted community health worker routines threaten to exacerbate limited access to care and negatively impact women's health. ${ }^{16}$

Evidence from similar health emergencies, most notably the Ebola outbreak in West Africa, has shown that such mitigating measures as well as the disease itself could have a detrimental impact on women and girls. The Ebola outbreak led to a $75 \%$ increase in maternal mortality in West Africa. This evidence suggests that COVID-19 will have a similar effect on women and girls. ${ }^{17}$

To the best of the investigators knowledge, there is no published research exploring the impact of the COVID-19 pandemic on antenatal care utilization among pregnant women in the country including our study setting. This is not only in Ethiopia, as very little is known about it in subSaharan African countries.

In order to fill this information gap in the scientific literature and in response to the limited evidence in the country, this study aims to assess the impact of the COVID-19 pandemic on antenatal care utilization among pregnant women attending public facilities in Northeast Ethiopia. Therefore, the result of this study will be beneficial to design strategies for prioritizing maternal healthcare, even with the COVID-19 pandemic period.

\section{Materials and Methods Study Setting}

The study was conducted in health facilities found in northeast Ethiopia, which is from south Wollo zone and Oromia special zone. The area is found in Amara national regional state, which is located $401 \mathrm{Km}$ from Addis Ababa, the capital city of Ethiopia. According to the 2019/2020 data obtained from zonal administration, the total population is 216,384 , and 115,114 of them are females. In the area there are four private and two governmental hospitals, eight health centers, and there are a number of private clinics and pharmacies. ${ }^{18}$ The 
financial coverage of ANC services in Ethiopia is cost free, covered by state.

\section{Study Design and Period}

A facility-based cross-sectional study was conducted among pregnant women who attended ANC in the selected health facilities from February 25 to August 30, 2020.

\section{Population}

The source population was all pregnant women who attended ANC in the selected health facilities, and all pregnant women who attended ANC in the selected health facilities during the data collection period was considered as our study population. Accordingly, a total of 389 pregnant women who fulfilled the inclusion criteria were included in the study.

\section{Sample Size Determination and Sampling Technique}

The sample size for prevalence of the study was determined using a single population proportion formula based on the following assumptions; level of confidence to be $95 \%, 5 \%$ margin of error, and taking the proportion of ANC utilization during the COVID-19 pandemic period as $50 \%$ since there was no previous study:

$$
N=\frac{\left(\frac{Z \alpha}{2}\right) 2 . \mathrm{P} . \mathrm{Q}}{(d)^{2}}=\frac{(1.96) 2(0.5 \times 0.5)}{(0.05) 2}=384
$$

where $\mathrm{Z}=1.96, \mathrm{~d}=5 \%, \mathrm{P}=50 \%$, and $\mathrm{Q}=50 \%$

By adding a $5 \%$ non-response rate, the sample size was 403 .

Sample size for factors influencing ANC utilization was calculated using a double population proportion with the assumption of $95 \%$ level of confidence, $80 \%$ power $\mathrm{d}=$ permitted error 5\%, P1 (percentage of outcome in unexposed group), ratio of exposed and unexposed group (1) and OR from previous literatures ${ }^{5,19}$ by using Epi-info version 7 software. Thus, the sample size for this study was 403 obtained from a single population proportion formula.

We have selected three hospitals purposively, ie, Dessie referral hospital, Kemise General Hospital, and Akasta General Hospital based on the number of catchment population and patient flow. Lists of pregnant women who came for ANC visit were extracted from the ANC registration log book in each Hospital.
The proportional size allocation was made from each selected public health facility based on the average number of ANC users in the most recent quarterly report of each health facility (157 participants from Dessie referral hospital, 113 participants from Akasta hospital, and 119 participants from Kemise general hospital). Study participants at each health facility were selected using a simple random sampling technique until the required sample size at each health facility was obtained.

\section{Study Variables and Operational Definition}

The outcome variable of the study was antenatal care utilization. Independent variables of the study were socio-demographic, socio-cultural, facility-related, and obstetric factors). Antenatal care utilization was defined as at least three antenatal care visits, consumed 90+ Iron and Folic Acid tablets, and two or more tetanus toxoid injections taken. Accordingly, if the pregnant women received the entire recommended antenatal care they wer coded as 1 ; if care was not received, they were coded as zero $(0){ }^{20}$

\section{Data Collection and Quality Assurance}

Data was collected using an interviewer-administered questionnaire which was developed after reviewing relevant literatures. ${ }^{1,7,12,13,19}$ The questionnaire comprised of socio-demographic, socio-cultural, and health facilityelated questions (supplementary material). About six BSc nurse data collectors and three public health officer supervisors were recruited in the data collection. To assure data quality, 2 days of training was given for data collectors and supervisors. In addition, a pretest was done on $10 \%$ of the sample at Woldia General Hospital before data collection. Furthermore, there was close day-to-day supervision of data collectors in the data collection process. Finally, it was checked for completeness and consistency.

\section{Data Management and Analysis}

All data was checked for inconsistencies, missing values, and incompleteness, then entered into Epi-data version 3.1 software and exported to STATA version 14 for further analysis. Descriptive statistics, including frequencies and proportions, were computed and presented in the form of text and tables. The binary logistic regression analysis was performed to identify factors associated with Antenatal 
care utilization for the meaningful interpretation of results. Enter method was used to select candidate variables having a $P$-value of $<0.2$ in the bi-variable analysis and entered to the multivariable analysis for controlling the possible confounders. Adjusted odds ratio (AOR) with 95\% CI was estimated to show the strength of association. Finally, a $P$-value of $<0.05$ in the multivariable logistic regression analysis was used to identify variables significantly associated with antenatal care utilization. HosmerLemeshow goodness of fit test was performed.

\section{Ethical Consideration}

Ethical clearance was released from the ethical review committee of the College of Medicine and Health Sciences, Wollo University. An official letter was obtained from the Amhara Public Health Institute, Dessie Branch, which in turn wrote a letter for each health facility to get permission. The purpose of the study was explained to the study participants, and verbal consent was also obtained from each of them. Verbal informed consent was approved by the Ethical Review Committee of the College of Medicine and Health Sciences, Wollo University, and this study was conducted in accordance with the Declaration of Helsinki. The participants under the age of 18 years were approved by the ethics committee to provide informed consent on their own behalf. Confidentiality of the responses was ensured throughout the research process.

\section{Results}

\section{Socio-Demographic Characteristics of}

\section{Respondents}

In this study, from the total of 403 pregnant women planned, 389 fully responded, giving a response rate of $96.52 \%$. Of these, $215(55.3 \%)$ respondents were in the age group of 25-34 years. The mean (standard deviation) age was 26 (4.4) years.

The majority of respondents $(370,95.1 \%)$ were married. In addition, 214 (55\%) had completed secondary school and above and $67.4 \%$ of them were housewives in occupation (Table 1).

\section{Impact of COVID-19 Pandemic on ANC Service Utilization}

The study revealed that $216(55.5 \%)$ respondents missed or were late to start ANC services during the COVID-19 pandemic period. Of these, $23(5.9 \%)$ were due to
Table I Socio-Demographic Characteristics of Pregnant Women Attending Antenatal Care at Public Health Facilities in North East Ethiopia During COVID-19 Outbreak, 2020 (n=389)

\begin{tabular}{|c|c|c|c|}
\hline Variables & Category & Frequency & Percent \\
\hline \multirow[t]{3}{*}{ Age } & $15-24$ & 143 & 12.1 \\
\hline & $25-34$ & 215 & 55.3 \\
\hline & $\geq 35$ & 31 & 8 \\
\hline \multirow[t]{2}{*}{ Residency } & Urban & 384 & 89.5 \\
\hline & Rural & 41 & 10.5 \\
\hline \multirow[t]{3}{*}{ Religion } & Muslim & 304 & 78.1 \\
\hline & Orthodox & 72 & 18.5 \\
\hline & Protestant & 13 & 3.3 \\
\hline \multirow[t]{3}{*}{ Occupational status } & House wife & 280 & 72 \\
\hline & Merchant & 70 & 18 \\
\hline & $\begin{array}{l}\text { Government } \\
\text { employee }\end{array}$ & 39 & 10 \\
\hline \multirow[t]{2}{*}{ Marital status } & Married & 370 & 95.1 \\
\hline & Unmarried & 19 & 4.9 \\
\hline \multirow[t]{5}{*}{ Educational status } & $\begin{array}{l}\text { No formal } \\
\text { education }\end{array}$ & 47 & 12.1 \\
\hline & Primary education & 128 & 32.9 \\
\hline & Secondary & 169 & 43.4 \\
\hline & education & & \\
\hline & College and above & 45 & 11.6 \\
\hline Monthly income (in & $\mathrm{I}, 88 \mathrm{I}-7,398$ & 331 & 85.1 \\
\hline ETB) & $\geq 7,399-22,086$ & 58 & 14.9 \\
\hline
\end{tabular}

deploying of maternal workers to COVID-19. The majority of respondents $(122,56.48 \%)$ reported it was due to fear of COVID-19 infection, followed by interruption and diversion of maternal services to COVID-19 (72, $33.33 \%)$.

Similarly, $66(17 \%)$ of the respondents reported they did not attend due to the stay at home principle and 28 (7.2\%) reported it was due to costly transportation during the lockdown period.

\section{Antenatal Care Services Utilization Among Pregnant Women}

From the total 389 pregnant women included in the study, $140(29.3 \%)$ who attended the obstetric outpatient clinics fully utilized the antenatal care services.

This result shows that most of the women (359, 92.3\%) received iron supplementation for $\geq 3$ months and 383 (98.5\%) of them were supplemented with folic acid. Regarding ANC visit the highest proportion (149, 38.3\%) of women had two visits only (Table 2). 
Table 2 Frequency Distribution of Antenatal Care Services During COVID-19 Pandemic Among Pregnant Women Attending Public Health Facilities in Northeast Ethiopia, 2020 $(n=389)$

\begin{tabular}{|c|c|c|c|}
\hline Variables & Category & $\begin{array}{l}\text { Frequency } \\
\text { (n) }\end{array}$ & $\begin{array}{l}\text { Percentage } \\
\text { (\%) }\end{array}$ \\
\hline ANC visit & $\begin{array}{l}\text { First } \\
\text { Second } \\
\text { Third } \\
\text { Fourth and } \\
\text { above }\end{array}$ & $\begin{array}{l}120 \\
149 \\
113 \\
7\end{array}$ & $\begin{array}{l}30.8 \\
38.3 \\
29.0 \\
1.8\end{array}$ \\
\hline $\begin{array}{l}\text { TT vaccination } \\
\text { status }\end{array}$ & $\begin{array}{l}1 \\
\geq 2\end{array}$ & $\begin{array}{l}149 \\
232\end{array}$ & $\begin{array}{l}38.3 \\
59.6\end{array}$ \\
\hline $\begin{array}{l}\text { Iron } \\
\text { supplementation }\end{array}$ & $\begin{array}{l}\text { I-2 month } \\
\geq 3 \text { months }\end{array}$ & $\begin{array}{l}24 \\
359\end{array}$ & $\begin{array}{l}6.1 \\
92.3\end{array}$ \\
\hline $\begin{array}{l}\text { Folic acid } \\
\text { supplementation }\end{array}$ & $\begin{array}{l}\text { Yes } \\
\text { No }\end{array}$ & $\begin{array}{l}383 \\
6\end{array}$ & $\begin{array}{l}98.5 \\
1.5\end{array}$ \\
\hline
\end{tabular}

\section{Predictors of Antenatal Care Utilization During COVID-19 Pandemic}

Among factors considered in the study women's age, residence, education status, history of stillbirth, interruption, and diversion of maternity services to COVID-19 response, fear of COVD-19 infection, and transport inaccessibility were major predictors for antenatal care utilization.

Multivariable analysis revealed that mothers aged $\geq 35$ years were 12-times more likely to utilize ANC services than mothers aged $\leq 24$ years $(\mathrm{AOR}=11.79,95 \% \mathrm{CI}=1.18$ 117.8). Mothers whose age was in the range of 25-34 years had increases of nearly 8-fold in ANC utilization as compared to mothers having age $\leq 24$ years $(\mathrm{AOR}=7.55$, 95\% CI=3.29-17.31).

The result of this study also revealed that urban resident mothers were 9-times more likely to utilize ANC services than mothers who were from rural areas (AOR=9.13, 95\% CI $=1.28-65.31)$.

Similarly, mothers who had no formal education were $79 \%$ less likely to utilize ANC services than those mothers who had secondary and above education $(\mathrm{AOR}=0.21,95 \%$ $\mathrm{CI}=0.05-0.96$ ). Respondents who had no history of stillbirth before recent pregnancy were $99.3 \%$ less likely to utilize ANC service than those who had a history of stillbirth before the recent pregnancy $(\mathrm{AOR}=0.007,95 \% \mathrm{CI}=0.001-0.12)$.

The result also revealed that interruption and diversion of maternal health-care services due to COVID-19 response reduces full service utilization by $32 \%$ ( $\mathrm{AOR}=0.68,95 \%$ $\mathrm{CI}=0.14-0.74)$. Transport accessibility increases the utilization of the ANC service by four unit folds as compared to those respondents who had no access to transportation (AOR=4.15, 95\% CI=1.04-16.54). Similarly, fear of COVID-19 infection reduces full service utilization by $87 \%$ (AOR $=0.13,95 \%$ CI $=0.06-0.31)$ (Table 3).

\section{Discussion}

The result of this study revealed that $29.3 \%$ of pregnant women fully received the recommended antenatal care services during the COVID-19 pandemic.

This finding was lower than in studies done in India $(45 \%),{ }^{20}$ Nepal $(87 \%),{ }^{21}$ Nigeria $(81.5 \%),{ }^{22}$ and Kenya $(52 \%){ }^{23}$ The result was also lower than local studies done in Ethiopia: Eastern Hararge (38.2\%), ${ }^{24}$ Holeta town $(66 \%),{ }^{9}$ Ethiopia $(32.5 \%),{ }^{25}$ and Debre Tabor town $(35.3 \%){ }^{5}$ The observed difference might be due to sociocultural and awareness differences, variations in sociodemographic characteristics, and the difference in study period (previous studies were conducted before the COVID-19 pandemic period, unlike the current study). Since in the pandemic period the antenatal care service utilization was found to be low this might be due to movement restrictions, fear of infection, and economic pressure, greater disruptions to health systems due to workforce and supply chain issues and the repurposing of health workers.

Our study showed that the age of respondents was positively and significantly associated with antenatal care service utilization. This finding was supported by studies done in Debre tabor, ${ }^{5}$ in hadya zone, southern Ethiopia, ${ }^{26}$ and Nigeria. ${ }^{11}$ This might be, as the age of the mother increases; they might have a better knowledge, understanding, and experience of pregnancy and pregnancy-related complications, which in turn increases the utilization of antenatal care services.

The result of this study also showed that mothers who have secondary education and above were more likely to utilize ANC services than mothers who have no formal education. Previous studies done in developing countries had found that higher educational level was highly associated with better antenatal care service utilization..$^{5,11,-26-28}$ This might be explained as women having better educational status are capable of identifying danger signs and easily understand the bad consequence of not attending antenatal care services. 
Table 3 Bi-Variable and Multivariable Logistic Regression Analyses of Factors Associated with Antenatal Care Utilization During COVID-19 Pandemic Among Pregnant Women Attending Public Health Facilities in Northeast Ethiopia 2020 (N=389)

\begin{tabular}{|c|c|c|c|c|c|}
\hline \multirow[t]{2}{*}{ Variables } & \multirow[t]{2}{*}{ Category } & \multicolumn{2}{|c|}{ ANC Utilization } & \multirow[t]{2}{*}{ COR $(95 \% \mathrm{Cl})$} & \multirow[t]{2}{*}{ AOR $(95 \% \mathrm{Cl})$} \\
\hline & & Yes & No & & \\
\hline \multirow[t]{3}{*}{ Age (years) } & $\leq 24$ & $36(25.17)$ & $107(74.83)$ & 1 & 1 \\
\hline & $25-34$ & $73(33.95)$ & $142(66.05)$ & $1.53(0.95-2.45)$ & $7.55(3.29-|7.3|)^{*}$ \\
\hline & $>35$ & $5(16.19)$ & $26(83.87)$ & $0.43(0.20-1.59)$ & $11.79(1.18-117.83)^{*}$ \\
\hline \multirow[t]{2}{*}{ Residence } & Urban & $109(31.3)$ & $239(68.7)$ & $3.28(1.25-8.59)$ & $9.13(1.28-65.31)^{*}$ \\
\hline & Rural & $5(12.2)$ & $36(87.8)$ & 1 & 1 \\
\hline \multirow[t]{3}{*}{ Education status } & $\begin{array}{l}\text { No formal } \\
\text { education }\end{array}$ & $12(25.5)$ & $35(74.5)$ & $0.58(0.29-1.19)$ & $0.21(0.05-0.96)^{*}$ \\
\hline & Primary & $23(18)$ & $105(82.0)$ & $2.78(0.70-3.45)$ & $0.84(0.17-4.17)$ \\
\hline & $\begin{array}{l}\text { Secondary and } \\
\text { above }\end{array}$ & $79(37)$ & $135(63)$ & 1 & 1 \\
\hline \multirow[t]{2}{*}{ History of still birth } & No & $25(67.57)$ & $12(32.43)$ & $6.16(2.97-12.76)$ & $0.007(0.001-0.12)^{*}$ \\
\hline & Yes & $89(25.28)$ & $263(74.72)$ & 1 & I \\
\hline Interruption of Maternity services due to & No & $36(50)$ & $36(50)$ & 1 & 1 \\
\hline COVID-19 & Yes & 239 (75.39) & $78(24.6 I)$ & $3.06(1.81-5.19)$ & $0.675(0.14-0.74)^{*}$ \\
\hline \multirow[t]{2}{*}{ Fear of COVID-19 } & No & $52(42.62)$ & $70(57.38)$ & 1 & I \\
\hline & Yes & $62(23.22)$ & $205(76.78)$ & $0.41(0.26-0.64)$ & $0.13(0.06-0.31)^{*}$ \\
\hline \multirow[t]{2}{*}{ Transport access } & No & $5(17.86)$ & $23(82.14)$ & 1 & I \\
\hline & Yes & $109(30.19)$ & $252(69.81)$ & $1.99(0.74-5.37)$ & $4.15(1.04-16.54)^{*}$ \\
\hline
\end{tabular}

Notes: *Significantly associated; I, reference.

Abbreviations: COR, crude odds ratio; AOR, adjusted odd ratio; COVID-19, coronavirus disease.

This finding also revealed that urban residency was found to be significantly associated with the utilization of antenatal care. This finding was supported by studies done in Ethiopia using Mini DHS 2019. ${ }^{10,17}$ This might be because pregnant women living in urban areas may have better access to health facilities and better awareness about the importance of ANC utilization.

A statistically significant association was also obtained between history of still birth and antenatal care service utilization. Mothers who had experienced stillbirth before were more likely to fully utilize ANC service than mothers who had not encountered it before. This finding was in line with another study done in Ethiopia. ${ }^{6,26}$ The possible explanation for this might be because those who faced still birth knew the risks associated with it; as a result they might fully utilize antenatal care in order to prevent it and to have a good pregnancy outcome.

Fear of COVID-19 infection was also found to be significantly associated with an $87 \%$ reduction in full ANC service utilization. Consistent to this in Bnei Brak, a city in Israel, one of the significant issues faced in maternal care was fear. Many women were anxious about contracting the coronavirus and feared going to prenatal checks, with some pregnant women staying away from the services altogether. ${ }^{29}$ This might be due to low awareness creation from the responsible body, and the preventive principles of COVID-19 might not be practiced properly. Fear of physical proximity may also limit or alter care provision. In addition, the fear of spreading the disease may lead health workers to deny mothers the service. Pregnant women have been reported to have experienced increased anxiety as a result of COVID-19. ${ }^{30,31}$ Similarly, a survey conducted in Italy among 100 pregnant women showed there was a fear of visiting hospitals for childbirth because they were scared of being infected themselves or feared vertical transmission. ${ }^{32}$

This study also showed that lack of transport accessibility increases the risk of not utilizing ANC services fully. Similarly, in Nepal, cases have been reported where, due to a lack of transportation, women developed complications on the way to the hospital and died at the health facility before receiving proper care. ${ }^{33}$ This might be because stay-at-home orders lead to greater lost income, reduced purchasing power, and the inability to pay for 
services doubling the cost of public, which in turn limit utilization of ANC services.

This finding also revealed that interruption and diversion of maternal health-care service reduces full service utilization by $32 \%$. Similarly, studies conducted during the pandemic in the Asia pacific region reported the service utilization would decrease to half. ${ }^{34}$ Consistently, in the US, some facilities have converted maternity wards to COVID-19 units, in order to accommodate the increasing number of COVID-19 patients. ${ }^{35}$ In India and Nepal the pandemic also has exposed shortfalls in the health system, with the majority of health facilities being ill equipped to deal with the pandemic. ${ }^{35-37}$

The situation is harsher in developing countries due to the lack of proper infrastructure and resources. ${ }^{37}$ This might be due to health system collapse or intentional choices made in responding to the pandemic, workforce reduction, access reduction, and also some health facility restricted number of ANC visits due to fear of the pregnant women contracting coronavirus.

The cross-sectional nature of this survey research was one of the main limitations of this study. Thus, unadjusted for temporal trends and no follow-up were also the limitations of the study. Furthermore, this study was not supplemented with the quantitative method of data collection.

\section{Conclusion and Recommendation}

The findings of this study showed the pandemic reduced the utilization of antenatal care services among pregnant women in the study area. Thus, the age of the mother, residency, educational status, history of still birth, interruption, and diversion of maternity health-care service, fear of COVID-19 pandemic, and transport inaccessibility were significant factors which contributed to the low antenatal care service utilization of pregnant women.

Thus, efforts to enhancing maternal health services should be recommended. Various IEC (Information, Education and Communication) materials will be produced to raise awareness regarding the protection of pregnant women during the COVID-19 pandemic. It is also better to start phone-in services to help with transportation to pregnant women. In addition, virtual consultation with obstetricians will be provided via telemedicine services, to women seeking maternal health services.

\section{Implications of the Study}

COVID-19 has caused disruption of health services on the global scale, including MHS (maternal health services).
Due to this pandemic, women are facing more barriers to accessing maternal healthcare, including restrictions, transport challenges, anxiety, and fear over possibly being exposed to coronavirus. This study demonstrates addressing the identified factors would help to design appropriate strategies to improve MHS utilization during the pandemic. Effective preventive and clinical strategies are needed to control COVID-19 infection among pregnant women. Governments also need to make sure that women can access basic information to protect the health of themselves and their babies. Additionally, arrangements should be made for assuring proper means of transportation and availability of MHS (maternal health services) during lockdown.

\section{Abbreviations}

ANC, Antenatal care; COVID-19, Coronavirus disease; AOR, Adjusted odds ratio; CI, Confidence interval; COR, Crude odds ratio; EMDHS, Ethiopia Mini Demographic and Health Survey; FGA, Family guidance association; KM, Kilometer; MHS, maternal health service; WHO, World Health Organization.

\section{Acknowledgments}

Special thanks go to Dessie Referral Hospital, Kemisse General Hospital, and Akasta General Hospital for their good cooperation during the data collection period. The author would also like to acknowledge the data collectors, supervisors, and all personnel involved for the accomplishment of this work.

\section{Disclosure}

The author reports no conflicts of interest for this work.

\section{References}

1. Riley T, Sully E, Ahmed Z, Biddlecom A. Estimates of the potential impact of the COVID-19 pandemic on sexual and reproductive health in low-and middle-income countries. Int Perspect Sex Reprod Health. 2020;46:46. doi:10.1363/46e9020

2. Worldometer. Coronavirus update COVID-19 21 June 2020? WHO/ Regional office; 2020. Available from: https://www.afro.who.int/news/ update-covid-19-21-june-2020.

3. Akowuah JA, Agyei-Baffour P, Awunyo-Vitor D. Determinants of antenatal healthcare utilisation by pregnant women in third trimester in Peri-Urban Ghana. J Trop Med. 2018;2018:8.

4. Gebreyohannes Y, Ararso D, Mengistu F, Abay S, Hadis M. Improving antenatal care services utilization in Ethiopia: an evidence-based policy brief. Int J Health Econ Policy. 2017;2:111-117.

5. Ayalew TW, Nigatu AM. Focused antenatal care utilization and associated factors in Debre Tabor Town,northwest Ethiopia. BMC. 2018;11:819. 
6. Mary Ross-Davie JL, Brigante L, Livingstone C, et al., Guidance for antenatal and postnatal services in the evolving coronavirus (COVID-19) pandemic. 2020.

7. Basha GW. Factors affecting the utilization of a minimum of four antenatal care services in Ethiopia. Obstet Gynecol Int. 2019;2019:6. doi: $10.1155 / 2019 / 5036783$

8. Timothy Roberton EDC, Chou VB, Stegmuller, AR, et al. Early estimates of the indirect effects of the COVID-19 pandemic on maternal and child mortality in low-income and middle-income countries: a modelling study. Lancet Glob Health. 2020.

9. Birmeta K, Dibaba. Y, Woldeyohannes D. Determinants of maternal health care utilization in Holeta town, central Ethiopia. BMC Health Serv Res. 2013;13(1):256. doi:10.1186/1472-6963-13-256

10. Ali SA, Dero AA, Ali SA. Factors affecting the utilization of antenatal care among pregnant women: a literature review. J Preg Neonatal Med. 2018;2(2).

11. UNICEF. Maternal and newborn health and COVID-19. UNICEF Data; 2020.

12. ICF, EPHI. Ethiopia Mini Demographic and Health Survey 2019: Key Indicators. Rockville, Maryland, USA: EPHI and ICF; 2019.

13. Esegbona-Adeigbe S. Impact of COVID-19 on antenatal care provision. Eur J Midwifery. 2020. doi:10.18332/ejm/121096

14. Yassa M, Yassa A, Yirmibeş C, et al. Anxiety levels and obsessive compulsion symptoms of pregnant women during the COVID-19 pandemic. Turk J Obstet Gynecol. 2020;17(3):155-160. doi:10.4274/tjod.galenos.2020.91455

15. Ng QX, Lee EZ, Tay JA, Arulanandam S. Impact of COVID-19 'circuit-breaker' measures on emergency medical services utilisation and out-of-hospital cardiac arrest outcomes in Singapore. Emerg Med Australas. 2020. doi:10.1111/1742-6723.13668

16. Dorit Stein KW, Catherine Cantelmo HP. Estimating the Potential Impact of COVID-19 on Mothers and Newborns in Low- and MiddleIncome Countries. health policy plus; 2020.

17. Hutchinson, T.R.a.G. The secondary impacts of COVID-19 on women and girls in Sub-Saharan Africa 2020.

18. Abdulhamid. Dessie town total population. Dessie: D.t.h.o. administration; 2020.

19. Assfaw YT, Sebastian MS. Determinants of antenatal care, institutional delivery and skilled birth attendant utilization in Samre Saharti District, Tigray, Ethiopia. Umeå International School of Public Health; 2010.

20. Chimankar D, Sahoo H. Factors influencing the utilization of maternal health care services in Uttarakhand. Stud Ethno-Med. 2011;5:209-216. doi:10.1080/09735070.2011.11886411

21. Tuladhar H, Dhakal N. Impact of antenatal care on maternal and perinatal utcome: a study at Nepal Medical College Teaching Hospital. Nepal J Obstet Gynaecol. 2011;6(2):37-43. doi:10.3126/ njog.v6i2.6755

22. Fagbamigbe AF, Idemudia ES. Assessment of quality of antenatal care services in Nigeria: evidence from a population-based survey. Reprod Health Med Care Serv Rev. 2015;12(1):88.

23. Gitonga E. Determinants of focused antenatal care uptake among women in Tharaka Nithi County, Kenya. Adv Public Health. $2017 ; 3685401$.
24. Zelalem Ayele D, Belayihun B, Teji K, et al. Factors affecting utilization of maternal health care services in Kombolcha District, Eastern Hararghe Zone, Oromia Regional State, Eastern Ethiopia. Int Sch Res Notices. 2014;2014.

25. CSACE I. Ethiopia demographic and health survey key indicator reports. Rockville: ICF; 2016:13-25.

26. Abosse Z, Woldie M, Ololo S. Factors influencing antenatal care service utilization in hadiya zone. Ethiop J Health Sci. 2010;20 (2):75-82.

27. Nebeb GT, Salgedo W, Alemayehu Y. Antenatal care utilization in Debre Tabor, North West Ethiopia. Gynecol Obstet. 2015;5:2161-2932.

28. Mulat G, Kassaw. T, Aychiluhim M. Antenatal care service utilization and its associated factors among mothers who gave live birth in the past one year in Womberma Woreda, North West Ethiopia. Epidemiology. 2015;2.

29. WHO. Coronavirus and pregnancy-preserving maternal health across the European Region. Available from https://www.euro.who.int/en/ health-topics/Life-stages/maternal-and-newborn-health/news/news/ 2020/6/coronavirus-and-pregnancy-preserving-maternal-healthacross-the-european-region.

30. Saccone G, Florio A, Aiello F, et al. Psychological impact of coronavirus disease 2019 in pregnant women. Am J Obstet Gynecol. 2020;223(2):293-295. doi:10.1016/j.ajog.2020.05.003

31. Durankuş F, Aksu E. Effects of the COVID-19 pandemic on anxiety and depressive symptoms in pregnant women: a preliminary study. J Matern-Fetal Neonatal Med. 2020;1-7. doi:10.1080/ 14767058.2020.1763946

32. de Freytas-tamura K. Pregnant and Scared o'Covid Hospitals, They're Giving Birth at Home. TheNewYorkTimes. 2020; Available from: https:/www.nytimes.com/2020/04/21/nyregion/coronavirushome-births.html.

33. Poudel A. A 200 percent increase in maternal mortality since the lockdown began. The Kathmandu Post; 2020. Available from:https:// kathmandupost.com/national/2020/05/27/a-200-increase-in-maternal -mortality-since-thelockdown-began.

34. BeniDDe,Maurizi oF. Coronavirus is leaving pregnant women with tough choices and bleaker outcomes. World Economic Forum; 2020 [cited Jun 22, 2020]. https://www.weforum.org/agenda/2020/05/ women-children-covid19srhmortality-rates/.

35. Stein D, Ward K, Cantelmo C. Estimating the potential impact of COVID-19 on mothers and newborns in low- and middle-income countries. Health Policy Plus. 2020.

36. Human Rights Watch. Africa: covid-19 exposes healthcare shortfalls. Human RightsWatch; 2020 [cited June 22, 2020]. Availablefrom: https://www.hrw.org/news/2020/06/08/africa-covid-19exposeshealthcare-shortfalls.

37. Mohanty P. Coronavirus Lockdown III: is Indias public healthcare system prepared tofighttheCOVID-19menace? BusinessToday. 2020. Available from: https:/www.businesstoday.in/current/economypolitics/coronavirus-lockdowncovid-19-pandemic-public-healthcaresystemdoctors-nursespatients/story/400039.html.

\section{Publish your work in this journal}

The International Journal of Women's Health is an international, peerreviewed open-access journal publishing original research, reports, editorials, reviews and commentaries on all aspects of women's healthcare including gynecology, obstetrics, and breast cancer. The manuscript management system is completely online and includes a very quick and fair peer-review system, which is all easy to use. Visit http://www.dovepress.com/testimonials.php to read real quotes from published authors. 